\title{
Glacier flow measurement and radio-echo sounding at Aurora Peak, Alaska, in 2008
}

\author{
Takehiro FUKUDA, ${ }^{1,2}$ Shin SUGIYAMA, ${ }^{2}$ Sumito MATOBA, ${ }^{2}$ Takayuki SHIRAIWA ${ }^{2}$ \\ ${ }^{1}$ Graduate School of Environmental Science, Hokkaido University, Sapporo 060-0810, Japan \\ ${ }^{2}$ Institute of Low Temperature Science, Hokkaido University, Sapporo 060-0819, Japan \\ E-mail: takefd@pop.lowtem.hokudai.ac.jp
}

\begin{abstract}
As part of a deep ice-core drilling project, GPS and ice-radar measurements were made in the vicinity of Aurora Peak, Alaska, USA. Surface and bed elevation maps were obtained over an area of $400 \mathrm{~m} \times \mathbf{7 0 0} \mathrm{m}$, which includes the drilling site. Surface flow velocity was measured at 18 locations in the same area. The results showed that the drilling site was situated on a gentle north-south ridge with saddle-shaped surface geometry. The horizontal ice-flow velocity at the drilling site was $<0.5 \mathrm{~m} \mathrm{a}^{-1}$ and the ice generally flowed eastward and westward along the surface slope. The glacier bed slopes to the east and has more complex topography than the ice surface. The drilling site was situated above a bedrock dip, with an ice thickness of $252 \pm 10 \mathrm{~m}$. These data constitute important information for estimating the effect of ice flow to the ice core retrieved from the depth of up to $180.17 \mathrm{~m}$.
\end{abstract}

\section{INTRODUCTION}

A number of ice cores have been drilled in the glaciers in Alaska and along the western coast of Canada (e.g. Holdsworth and others, 1992; Wake and others, 2002; Shiraiwa and others, 2003, 2004). These ice cores help us to better understand the climate and material transport systems in the North Pacific and on the western coast of North America. For example, an ice core from Mount Logan, Canada, was used to investigate the connection between the climate signals of the western coast of North America and the eastern coast of Asia (Holdsworth and others, 1992; Holdsworth, 2001). Oxygen isotopes, the accumulation rate and impurity signals from the Eclipse ice core were found to be a useful proxy for regional climate histories (Wake and others, 2002). Transport of Asian dust to North America was investigated by analyzing ice drilled at Mount Wrangell, Alaska, with high temporal resolutions (Yasunari and others, 2007).

Despite the previous studies described above, ice-core studies have never been reported for the Alaska Range, located in the interior of Alaska. Considering the spatial variabilities of the climate and atmospheric conditions over the mountainous terrain, it is crucial that the ice-core information for this region is expanded. Moreover, a longerterm paleoenvironmental record can be expected in an ice core from the Alaska Range, as precipitation is less than in the coastal area. As part of the Japanese ice-core drilling project in the North Pacific regions, ice-core drilling was carried out at Aurora Peak in the Alaska Range from May to June 2008.

Aurora Peak $\left(63^{\circ} 31^{\prime} 16.13^{\prime \prime} \mathrm{N}, 146^{\circ} 32^{\prime} 43.85^{\prime \prime} \mathrm{W} ; 3068 \mathrm{~m}\right.$ a.s.l.) is located in the eastern part of the Alaska Range. Drilling and glaciological research activities were carried out in a snow-covered flat field situated $1200 \mathrm{~m}$ northeast of Aurora Peak (Figs 1 and 2). The study site is the source of three glaciers: Black Rapids, Sustina and Trident Glaciers. We conducted drilling and other field activities from 18 May to 9 July 2008 at the center of the flat field $\left(63^{\circ} 31^{\prime} 51.2769^{\prime \prime} \mathrm{N}\right.$, $146^{\circ} 32^{\prime} 00.1607^{\prime \prime}$ W; 2821 ma.s.l.). After 3 weeks of drilling, we obtained a $180.17 \mathrm{~m}$ long ice core.

In addition to the drilling, we performed GPS measurements to obtain glacier surface elevation and ice-flow velocity, and ice-radar measurements to obtain glacier bed elevation. The surface geometry and velocity field are important requirements for evaluating the advection of ice into the drilling site. Bedrock geometry provides clues to the formation of the glacier and the nature of the ice near the bed. The aim of this paper is to report on the GPS and icepenetrating radar measurements and present the results obtained for the surface and bed geometry, ice thickness distribution and surface ice flow field.

\section{METHOD}

\subsection{Surface elevation}

Two sets of dual-frequency GPS (Leica Geosystems System 1200) were used to measure the surface elevation with a kinematic positioning mode, which is one of the carrierphase differential GPS techniques (e.g. Eiken and others, 1997). One GPS was used as a reference station. The reference GPS antenna was fixed on the top of a $1 \mathrm{~m}$ long pole that was stuck in the snow surface $\sim 5 \mathrm{~m}$ west of the drilling site. GPS satellite signals were recorded every $1 \mathrm{~s}$. Another GPS was mounted on a $2 \mathrm{~m}$ long pole to serve as a rover station; we used this for elevation measurements while moving over the glacier. The survey was carried out in an area of $400 \mathrm{~m} \times 700 \mathrm{~m}$, which included the ice-core drilling site. We set a survey profile along the north-south direction, passing through the drilling site, and 16 orthogonal profiles in the west-east direction (Fig. 3a). Measurements were performed every $\sim 20 \mathrm{~m}$ along the profiles. Three-dimensional coordinates relative to the reference station were computed by post-processing the data with GPS analysis software (Leica GeoOffice). The software reported maximum root-mean-square (RMS) errors of $8.1 \mathrm{~mm}$ in the horizontal and $14.0 \mathrm{~mm}$ in the vertical directions.

\subsection{Surface flow velocity}

Surface flow velocity was measured by surveying poles stuck in the glacier surface with a static positioning technique. The same reference station as that for the kinematic positioning was used. The motion of the reference station during the measurement period was evaluated using data from a permanent GPS station operated by the Plate Boundary 


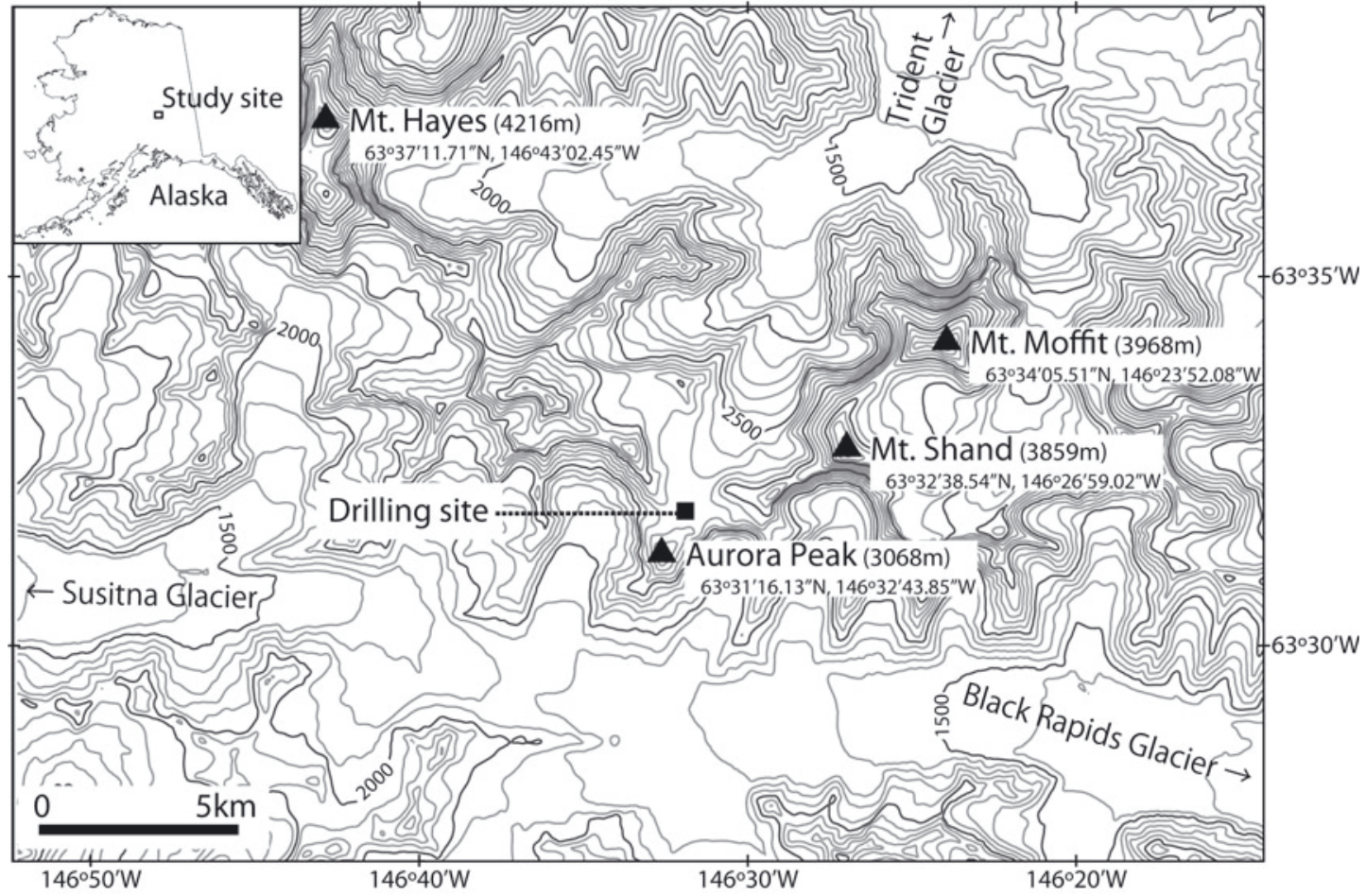

Fig. 1. Map of the study site. The contours show the surface elevation at $100 \mathrm{~m}$ intervals. The digital elevation data were obtained from the National Elevation Dataset of the US Geological Survey. Inset shows the location of Aurora Peak in Alaska.

Observatory (http://www.unavco.org/) 34 km east of the study site. Horizontal motion of the reference station over 3 weeks was within $\pm 30 \mathrm{~mm}$, which was nearly equal to the GPS positioning accuracy for a $34 \mathrm{~km}$ long baseline. From this observation, we conclude that the horizontal motion of the reference station was $<0.5 \mathrm{~m} \mathrm{a}^{-1}$. In the vertical direction, the reference station moved downward at a rate of $8.0 \mathrm{~m} \mathrm{a}^{-1}$. We used this rate to compensate for the temporal variation in the elevation of the reference station height in the vertical velocity calculation.

The second antenna was mounted on top of a $1 \mathrm{~m}$ long wooden pole installed $>0.5 \mathrm{~m}$ deep in the snow surface. No tilting nor subsidence of the pole was observed during the measurement period. The GPS satellite signals were recorded every $30 \mathrm{~s}$ for $\sim 1$ hour. We installed 18 poles forming a $100 \mathrm{~m}$ grid around the drilling site (Fig. 3b). Each pole was surveyed twice at intervals of $\sim 10$ days within the period 20 May-9 June 2010. The software reported RMS errors of 4.4 and $6.9 \mathrm{~mm}$ in the horizontal and vertical directions, respectively. Thus the error in the measured velocity was $<0.1 \mathrm{~m} \mathrm{a}^{-1}$.

\subsection{Ice thickness}

We used an ice-penetrating radar system manufactured by The Ohio State University, USA, which is based on a design proposed by R.S. Vickers and R.L. Bollen (unpublished information). The system is composed of a transmitter, receiver and $20 \mathrm{~m}$ long dipole antennae. The transmitter radiates electromagnetic waves (central frequency $5 \mathrm{MHz}$ ) in the form of a short high-voltage pulse. The ice thickness measurement was carried out every $20 \mathrm{~m}$ along seven profiles (Fig. 3c). The distance between the transmitter and receiver was $20 \mathrm{~m}$. We measured wave propagation speed in the glacier using the common-midpoint method (Hambrey and others, 2005). The distance between the transmitter and receiver was changed from $10 \mathrm{~m}$ to $100 \mathrm{~m}$ with intervals of $10 \mathrm{~m}$ by fixing the midpoint.

\section{RESULT}

\subsection{Surface elevation}

The glacier surface elevation map obtained by this study is shown in Figure 3a. The elevation shown in the plot is relative to our GPS reference station (2821 ma.s.I.). The survey results revealed a saddle-shaped geometry with a ridge extending north-south, and side slopes becoming progressively steeper towards the east and west. The drilling site was located near the highest point of the saddle.

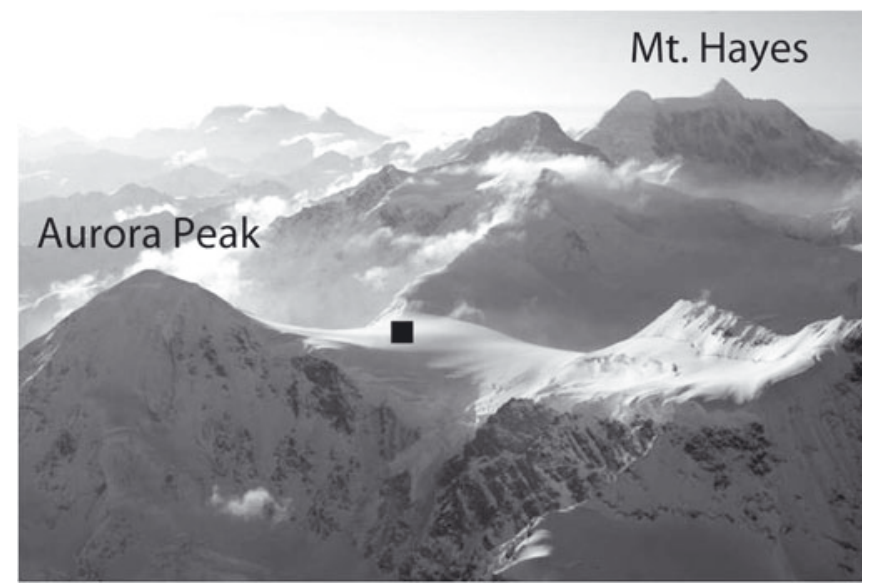

Fig. 2. Study site viewed from southeast. The ice-core drilling site is indicated by the solid square. Photograph taken by R. Homberger on 12 April 2008. 

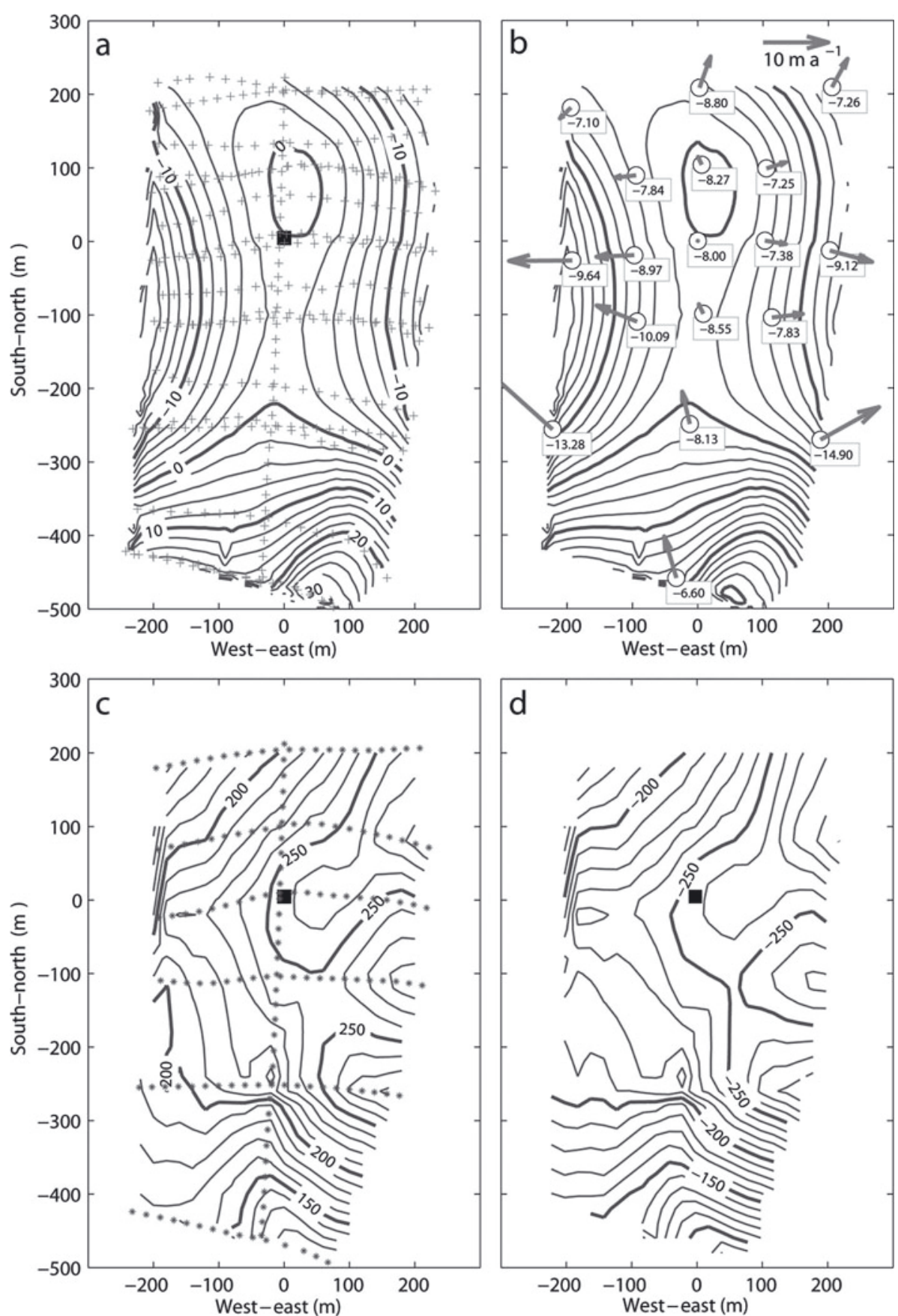

Fig. 3. (a) Surface elevation measured by this study, with contour intervals of $2 \mathrm{~m}$. The elevation and horizontal coordinates are relative to our GPS reference station (2821 m a.s.l.) situated near the drilling site indicated by the solid square. The surface elevation measurements were carried out at the locations indicated by + . (b) Locations of the flow velocity measurements ( 0 ) and horizontal velocity vectors (arrow) measured from 20 May to 9 July 2008. Vertical velocities are indicated by the digits (upward positive). The contour lines show the surface elevation as in (a). (c) Ice thickness distribution with contour intervals of $10 \mathrm{~m}$. Ice-radar measurements were carried out at the locations indicated by *. (d) Bedrock elevation relative to the GPS reference station with contour intervals of $10 \mathrm{~m}$.

\subsection{Surface flow velocity}

The measured surface flow velocity is shown in Figure $3 b$. Smallest speeds were found near the topographic crest. The horizontal flow directions generally follow the surface slope. The velocity is greater on the western slope; the flow speed is up to $16.7 \mathrm{~m} \mathrm{a}^{-1}$ on the western slope, while it is $10.0 \mathrm{~m} \mathrm{a}^{-1}$ on the eastern slope. Vertical velocity is negative (downward) at all the measurement points and its magnitude is $>6.6 \mathrm{~m} \mathrm{a}^{-1}$. There is a large spatial variation in the vertical velocity. The greatest velocity is $-14.90 \mathrm{~m} \mathrm{a}^{-1}$ (188 $\mathrm{m}$ to the east and $270 \mathrm{~m}$ to the south of the drilling site), which is more than twice the smallest velocity of $-6.6 \mathrm{~m} \mathrm{a}^{-1}$ ( $33 \mathrm{~m}$ to the west and $458 \mathrm{~m}$ to the south of the drilling site). At the drilling site, a vertical velocity of $-8.00 \mathrm{~m} \mathrm{a}^{-1}$ was observed. Surface-parallel glacier motion accounts for up to $18 \%$ of the vertical velocity on the steep slopes and $<10 \%$ within the region $\pm 100 \mathrm{~m}$ from the drilling site.

\subsection{Ice thickness}

We determined ice propagation speed in the glacier as $184.9 \mathrm{~m} \mathrm{ss}^{-1}$, which is $\sim 10 \%$ greater than the value in solid ice (Glen and Paren, 1975). The deviation can be attributed 


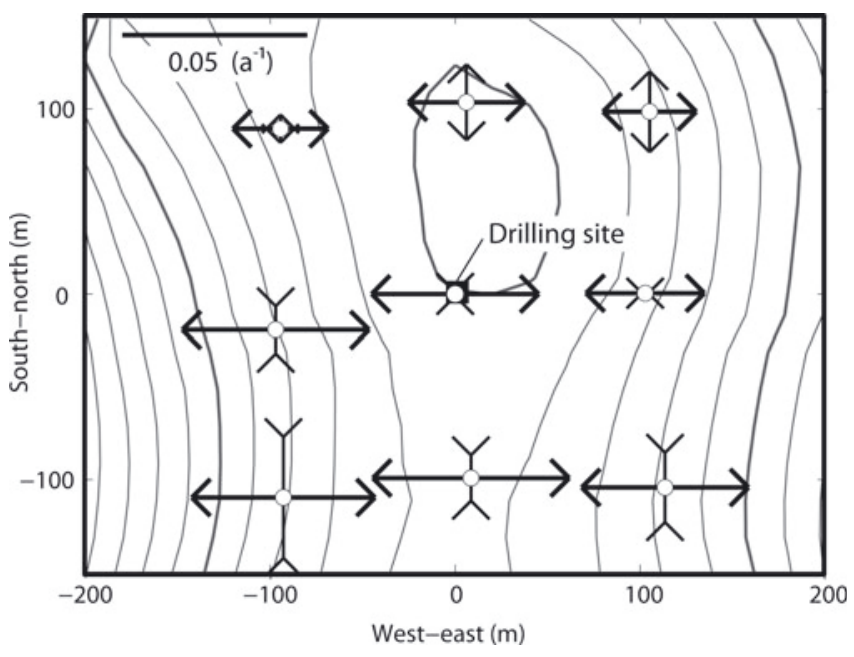

Fig. 4. Horizontal strain rates computed from the flow velocities observed at adjacent measurement sites.

to the effects of a surface firn layer (Bogorodsky and others, 1985). Our value is in good agreement with those reported in previous studies for alpine glaciers (Matsuoka and others, 1999; Kanamori and others, 2005). The obtained propagation speed was used to calculate the ice thickness along the seven measurement profiles.

The ice thickness distribution is shown in Figure 3c. The glacier is $252 \pm 10 \mathrm{~m}$ thick at the drilling site. This result indicates that we drilled up to $\sim 70 \%$ of the thickness. It should be noted that the ice thickness distribution is not similar to the surface geometry. Unlike the surface, which is inclined symmetrically in the east-west direction, the ice is $\sim 50 \mathrm{~m}$ thicker on the eastern side of the ridge than the western side.

\section{DISCUSSION AND CONCLUDING REMARKS}

The stake motion at $5 \mathrm{~m}$ from the drilling site was $<0.5 \mathrm{~m} \mathrm{a}^{-1}$, which confirms that the advection of ice from the surrounding regions is very small. Thus, the influence of horizontal ice motion on the ice core is considered to be small. The surface flow speed field shows that the ice is under a relatively simple tensile strain field in the east-west direction, caused by ice flow along the side slopes of the saddle-shaped geometry (Fig. 4). The east-west horizontal strain rate was computed as $0.045 \mathrm{a}^{-1}$ for the region extending $\pm 100 \mathrm{~m}$ to the east and west from the drilling site. The north-south strain rate is $\sim 2 \%$ of this value, showing the importance of the east-west flow regime in the vertical thinning of the ice core. The strain rate exactly at the drilling site should be much smaller than $0.045 \mathrm{a}^{-1}$, as it locates near the crest of the ridge, and may have been influenced by the migration of the ridge location in the past.

The bed geometry is not as simple as the surface (Figs 3d and 5). On the eastern side of the surface ridge, there are two trenches descending in the northeast and southeast directions, and the ice thickness is $>250 \mathrm{~m}$ along these trenches. The drilling site was above a small bedrock dip, situated at the head of the two trenches. Considering the irregularities in the bed geometry, the formation of the saddle-shaped surface topography is based on a complex balance of surface mass-balance and ice-flow distributions which might have been different in the past. If the surface topography has been changing in the past, annual layers in the deeper part of the ice core may have been influenced by the change of the ice-flow field. The bedrock dip suggests that ice is relatively stagnant near the bed and old ice is preserved at the drilling site. Nevertheless, care should be taken in interpreting the deepest part of the ice, as some influence of the complex geometry is expected near the bed.

The magnitude of the downward vertical velocity at the drilling site $\left(8.00 \mathrm{~m} \mathrm{a}^{-1}\right)$ was significantly greater than the thickness of annual snow layers determined by an isotope analysis of the ice core. The mean annual-layer thickness for the upper $35 \mathrm{~m}$ was $\sim 2.9 \mathrm{~m}$ w.e., which is equal to $5.9 \mathrm{~m}$ thick snow with a density measured for the upper $5 \mathrm{~m}$ $\left(490 \mathrm{~kg} \mathrm{~m}^{-3}\right.$ ) (A. Tsushima and others, unpublished information). The difference may be attributed to the fact that our

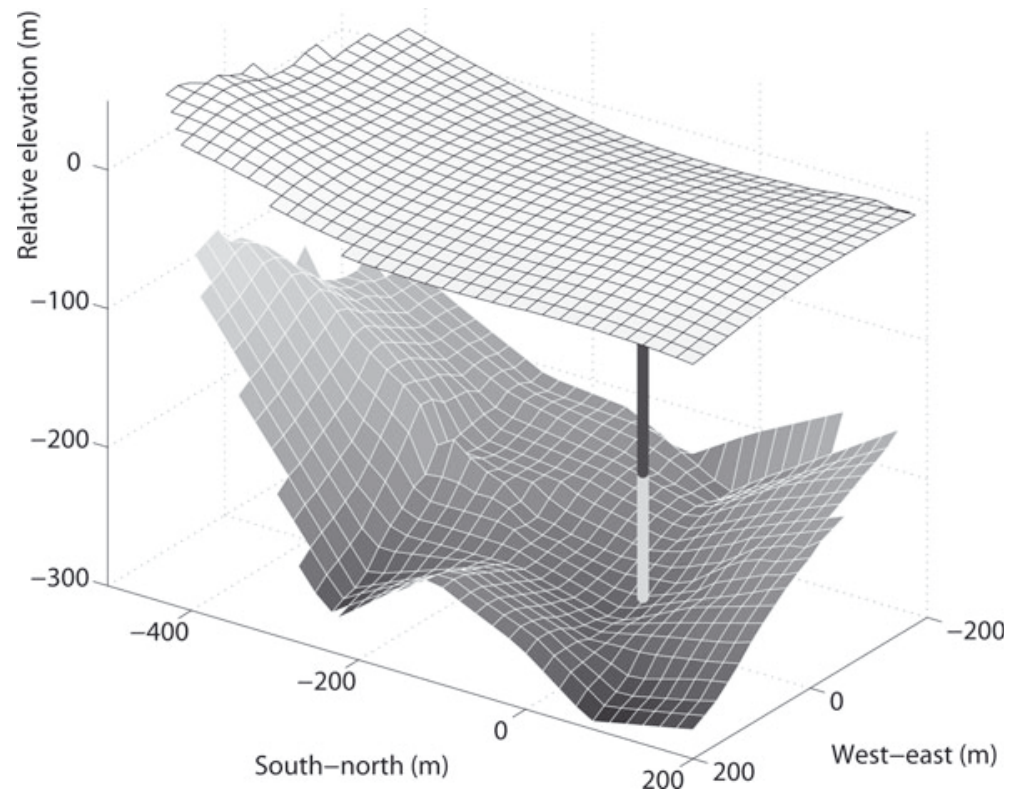

Fig. 5. Oblique view of the study site. Upper and lower surfaces show the glacier surface and bed, respectively. The grid size of the mesh is $20 \mathrm{~m} \times 20 \mathrm{~m}$. The vertical column indicates the drilling site, with dark gray representing the retrieved $180.17 \mathrm{~m}$ long ice core. 
velocity measurement was performed in the summer so that the rate of firn densification was greater than the annual mean. The effect of the horizontal stretching strain rate on the annual-layer thickness should also be considered. Nevertheless, there is a possibility that the accumulation is not sufficient to retain the current geometry, i.e. the glacier is thinning under current climate conditions.

\section{ACKNOWLEDGEMENTS}

We thank S. Okamoto, H. Sasaki, D. Solie and K. Yoshikawa for their help in the field. The field operation was supported by P. Claus of Ultima Thule Outfitters. The manuscript was handled by the scientific editor, S. Takahashi, and its quality was improved by review comments by K. Matsuoka and an anonymous referee. This research was funded by the Japanese Ministry of Education, Science, Sports and Culture, Grant-in-Aid for Scientific Research (B), 90235739, 2007-2009.

\section{REFERENCES}

Bogorodsky, V.V., C.R. Bentley and P.E. Gudmandsen. 1985. Radioglaciology. Dordrecht, etc., D. Reidel.

Eiken, T., J.O. Hagen and K. Melvold. 1997. Kinematic GPS survey of geometry changes on Svalbard glaciers. Ann. Glaciol., 24, 157-163.

Glen, J.W. and J.G. Paren. 1975. The electrical properties of snow and ice. J. Glaciol., 15(73), 15-38.
Hambrey, M.J. and 7 others. 2005. Structure and changing dynamics of a polythermal valley glacier on a centennial timescale: Midre Lovénbreen, Svalbard. J. Geophys. Res., 110(F1), F01006. (10.1029/2004JF000128.)

Holdsworth, G. 2001. Atmospheric teleconnection between Japan and the Saint Elias Mountains. Mem. Natl Inst. Polar Res., Special Issue 54, 161-168.

Holdsworth, G., H.R. Krouse and M. Nosal. 1992. Ice core climate signals from Mount Logan, Yukon A.D. 1700-1987. In Bradley, R.S. and P.D. Jones, eds. Climate since A.D. 1500. London, Routledge, 483-504.

Kanamori, S., Y. Ohkura, T. Shiraiwa and K. Yoshikawa. 2005. Snow-pit studies and radio echo soundings on Mt. McKinley 2004. Bull. Glacier Res., 22, 89-97.

Matsuoka, K. and 7 others. 1999. Radio echo sounding at the summit ice cap of Ushkovsky volcano, Kamchatka. In Naruse, R., ed. Cryospheric studies in Kamchatka II. Sapporo, Hokkaido University. Institute of Low Temperature Science, 20-24.

Shiraiwa, T. and 7 others. 2003. Ice core drilling at King Col, Mount Logan 2002. Bull. Glaciol. Res., 20, 57-63.

Shiraiwa, T., S. Kanamori, C.S. Benson, D. Solie and Ya.D. Murav'ev. 2004. Shallow ice-core drilling at Mount Wrangell, Alaska. Bull. Glaciol. Res., 21, 71-77.

Wake, C.P., K. Yalcin and N.S. Gundestrup. 2002. The climate signal recorded in the oxygen-isotope, accumulation and majorion time series from the Eclipse ice core, Yukon Territory, Canada. Ann. Glaciol., 35, 416-422.

Yasunari, T.J. and 7 others. 2007. Intra-annual variations in atmospheric dust and tritium in the North Pacific region detected from an ice core from Mount Wrangell, Alaska. J. Geophys. Res., 112(D10), D10208. (10.1029/2006JD008121.) 